\title{
ANALISIS PERBANDINGAN METODE JUST IN TIME DAN ECONOMIC ORDER QUANTITY
}

\author{
ADI SANTOSO \\ BRI Cabang Blitar \\ Jalan Raya Lorejo Bakung
}

\begin{abstract}
UD Surabaya Rattan Industry as the middle scale of company is produced rattan chairs. This company is based on the job order to plan and develop the future company to its business strategy become mass production. In process production, the company always faces problems in the row material supply. If the row material supply is saved in long time period and there is bulking in storage it can make the rattans will be under level quality. The purpose of this research is giving information about the choosing methods of planning, controlling the row material supply with differ between Just in Time (JIT) method with Economic Order Quantity (EOQ) to minimize inventory value. The result of from chosen method for the planning of inventory control of raw material. Total Inventory Cost (TIC) which in it there are three element of it expense of that is expense of purchasing, expense of ordering, and also stock holding cost got TIC for the Method of Just in Time (JIT) period 13 to Rp233.129.629,71. While for the Method of Economic Order of Quantity (EOQ) at period 13 to Rp234,171,969.21. Calculation of Total Inventory Cost (TIC) as a whole (period of time 1 year) by applying Method of Just In Time ( JIT) it can be seen Totalize Inventory Cost (TIC) Rp5,012,483,943.59 while by applying Economic Order of Quantity (EOQ) from Total of Inventory Cost (TIC) Rp518,088,399.86. Becoming method planning of inventory control the selected method of Just In Time (JIT) with thrift equal to Rp5,604,456.27.
\end{abstract}

Key words: just in time, economic order quatity, inventory

\section{PENDAHULUAN}

Seiring dengan perkembangan dunia industri di Indonesia, persaingan bisnis juga semakin meningkat, menuntut para pelaku bisnis untuk meningkatkan efisiensi di segala bidang. Salah satu cara untuk mewujudkannya dengan sistem perencanaan pengendalian persediaan yang baik proses produksi berjalan dengan lancar, sehingga permintaankonsumenakan dapat terpenuhidengan tepat waktu dan tidak terjadi keterlambatan.

Pada perusahaan manufaktur, persediaan dapat dibedakan menjadi tiga, yaitu: persediaan bahan baku, persediaan barang dalam proses, dan persediaan barang jadi. Pada umumnya dari ketiga macam bentuk persediaan tersebut, persediaan yang paling banyak menyerap biaya adalah persediaan bahan baku. Akan tetapi masih banyak perusahaan yang menyimpan persediaan bahan baku dalam yang cukup besar. Alasan utama mengapa perusahaan menyimpan bahan baku dalam jumlah besar adalah sebagai persediaan penyagga apabila terjadi keterlambatan pengiriman dari supplier sehingga proses produksi tidak terhenti, selain itu dengan pembelian dalam jumlah yang cukup besar perusahaan akan mendapatkan diskon sehingga mendapatkan harga bahan baku yang lebih murah. Pada kenyataannya, pengadaan bahan baku dalam jumlah yang cukup besar tidak selamanya menguntungkan sebab perusahaan harus menyiapkan dana yang cukup besar untuk pembelian persediaan, seharusnya dana tersebut masih dapat digunakan untuk membiayai kegiatan perusahaan yang lainnya. Selain itu biaya penyimpanan yang menjadi tanggungan perusahaan semakin besar dengan adanya risiko kerusakan, kadaluarsa, penurunan kualitas, kehilangan, dan lain sebagainya, dan yang terakhir adalah adanya resiko kerugian apabila terjadi penurunan harga pasar.

UD Surabaya Rattan Industry adalah perusahaan milik perseorangan, yang berlokasi di daerah Menganti - Gresik. UD. Surabaya Rattan Industry sebagai perusahaan berskala menengah merupakan suatu usaha dagang yang bergerak dalam bidang pembuatan kursi rotan. Untuk saat ini perusahaan berdasarkan job order, untuk rencana 
ke depan perusahaan akan mengembangkan strategi bisnisnya menjadi mass production.

Dalam menjalankan proses produksinya perusahaan sering mengalami permasalahan pada persediaan bahan baku dasar. Apabila persediaan bahan baku seperti kayu rotan disimpan dalam jangka waktu yang lama dan terjadi penumpukan di gudang maka bukan tidak mungkin kayu rotan tersebut akan mengalami keusangan dan kerusakan. Pada sisi ini perusahaan dihadapkan pada besarnya biaya persediaan akan banyaknya biaya persediaan yang diserap dan keusangan. Kondisi ini dapat menurunkan mutu bahan baku, karena turunnya mutu produk yang dihasilkan oleh perusahaan seringkali diikuti dengan turunnya harga jual produk. Pada sisi lain karena harga bahan baku yang terus naik, perusahaan berusaha menimbun bahan baku dengan membeli bahan baku dalam jumlah yang cukup besar untuk mendapatkan keuntungan membeli bahan baku dengan harga yang murah. Tetapi terkadang perusahaan juga sering mengalami kekurangan bahan baku yang mengakibatkan perusahaan tidak siap untuk melayani permintaan konsumen sehingga pesanan akan produk terpaksa ditolak oleh perusahaan.

Berdasarkan uraian permasalahan di atas diketahui bahwa perusahaan belum menggunakan metode yang tepat untuk menentukan berapa besar jumlah bahan baku dan kapan tersebut dipesan. Untuk menjawab persoalan berapa jumlah bahan baku dan kapan bahan baku dipesan agar dapat meminimalisasi Total Inventory Cost, maka penting dilakukan perbandingan metode Just In Time (JIT) dengan metode Economic Order Quantiy (EOQ). Metode Just In Time (JIT) digunakan untuk menentukan jumlah pemesanan yang ekonomis untuk setiap kali pemesanan dengan frekuensi pemesanan yang lebih sering, serta memanfaatkan kemampuan pemasok bahan baku (supplier) untuk menyerahkan pesanan tepat pada saat dibutuhkan dan pada tingkat yang dibutuhkan saja. Metode Economic Order Quantity (EOQ) digunakan untuk menentukan berapa jumlah pemesanan yang ekonomis untuk setiap kali pemesanan dengan frekuensi pemesanan yang telah ditentukan serta kapan pemesanan dilakukan kembali (reorder point). Tujuan penelitian ini membandingkan antara metode Just In Time (JIT) dan Economic
Order Quantity (EOQ) untuk meminimalkan biaya inventory, dan mengetahui hasil dari metode yang terpilih untuk perencanaan pengendalian persediaan bahan baku.

\section{METODE}

Penelitian ini menggunakan 2 jenis sumber data, yaitu data primer dan data sekunder.

Data primer: merupakan data yang diperoleh melalui pengamatan langsung dari sumbernya, diamati, dicatat untuk pertama kalinya oleh peneliti dari pihak yang menjadi objek penelitian. Data ini diperoleh melalui wawancara langsung dengan pihak yang bersangkutan dan dokumentasi perusahaan.

Data Skunder: merupakan data yang bukan diusahakan sendiri pengumpulannya oleh peneliti. Adapun sebagai sumber data sekunder adalah pihak intern perusahaan yang menjadi objek penelitian maupun pihak ekstern. Selain dari perusahaan, data ini biasanya didapat dari Badan Pusat Statistik, Departemen Perindustrian dan Perdagangan, majalah dan buletin.

Data yang diperlukan dalam penelitian ini meliputi data jumlah hari kerja, data jenis dan komponen produk, data permintaan produk, data persediaan dan pemakaian bahan baku, data biaya, persediaan tahap selanjutnya yaitu:

Metode analisis yang digunakan dalam penelitian ini adalah metode analisis kuantitatif. Adapun tahapan-tahapan pengolahan data yang dilakukan dalam penelitian ini adalah sebagai berikut. (1) meramalkan permintaan produk (produk demand forecasting) berdasarkan data historis permintaan produk. Pengolahan peramalan dalam analisis ini memakai program Minitab 13, yang di dalamnya menyangkut masalah peramalan (forecasting). Dalam penelitian ini menggunakan 3 model peramalan diantaranta Linier Trand Model, Quantintatic Trend Model dan Expontential Trend Model. (2) Membuat rencana besarnya persediaan bahan baku yang diperlukan oleh perusahaan dengan menggunakan metode Just in Time (JIT) dengan sistem kanban pemasok dan Economic Order Quantity (EOQ) model Q berdasarkan rencana produksi yang telah dibuat (Biegel, Jhon E., 1992). (3) Menganalisis hasil penerapan metode Just in Time (JIT) dengan 
sistem kanban pemasok dan Economic Order Quantity (EOQ) model Q dengan cara membandingkan tingkat Inventory rata-rata (I) dan Total Inventory Cost (TIC). (4) Membuat rencana pemesanan bahan baku dasar berdasarkan metode perencanaan pengendalian persediaan bahan baku yang terpilih.

\section{HASIL DAN PEMBAHASAN}

Hasil Tabel 1 merupakan hasil rencana produksi bulanan dan harian produk kursi parabola dan kursi sofa. Peramalan permintaan produk kursi parabola dan kursi sofa dalam kurun waktu periode kedepan, menggunakan metode linier trend model, quadratic trend model dan exponential trend model. Parameter yang digunakan dalam mengevaluasi ketiga metode peramalan tersebut menggunakan metode Mean Absolute Devlation (MAD) dengan nilai MAD yang paling kecil, pengertiannya bahwa dengan nilai MAD yang terkecil diharapkan keakuratan peramalan tinggi sehingga penyimpangan yang terjadi sangat kecil (Pujawan, 1995).

Rencana produksi atau priority planning diperlukan untuk memenuhi permintaan produksi kursi parabola dan sofa. Perencanaan produksi berfungsi untuk mengantisipasi terjadinya kekurangan jumlah produk.

Setelah jumlah produksi yang direncanakan diperoleh maka diperlukan jumlah kuantitas kebutuhan bahan baku (rotan) yang dipakai untuk membuat produk kursi parabola dan kursi sofa berdasarkan jumlah unit produk. Untuk menerapkan Metode Just in Time (JIT) maka rencana produksi bulanan harus ditranformasikan ke dalam rencana produksi harian guna mendapatkan rencana kebutuhan bahan baku harian. Hal ini dalam satuan lonjor ditunjukkan pada Tabel 2.

Setelah rencana produksi harian diketahui dari pembagian rencana produksi bulanan dengan jumlah hari kerja tiap bulannya, maka rencana kebutuhan bahan baku harian dalam satuan $\mathrm{kg}$ dapat diketahui sebagaimana ditunjukkan pada Tabel 3.

Untuk Metode Just in time (JIT), pemesanan bahan baku menggunakan sistem Kanban pemasok, berdasarkan hasil perhitungan penentuan jumlah kartu Kanban diketahui bahwa frekuensi pengiriman bahan baku adalah $22 \mathrm{kali} / \mathrm{bulan}$ dan 1 kartu Kanban memiliki kuantitas Just in Time (JIT) untuk 1 kali pesan adalah $1200 \mathrm{~kg}$.

Rencana kebutuhan bahan baku dengan metode EOQ (Economic Order Quantity). Ditunjukkan pada Tabel 4. Dengan menggunakan model Q karena adanya fluktuasi kuantitas permintaan produk pada data histories sehingga permintaan akan kebutuhan bahan baku juga mengalami fluktuasi.

Berdasarkan perhitungan rencana pemesanan bahan baku dengan Metode EOQ (Economic Order Quantity) didapat jumlah kuantitas pemesanan bahan baku yang paling ekonomis untuk periode 13 sebesar 6961,84 kg dengan frekuensi

Tabel 1. Rencana Produksi Bulanan dan Harian

\begin{tabular}{|c|c|c|c|c|c|}
\hline \multirow[t]{2}{*}{ Bulan } & \multirow{2}{*}{$\begin{array}{c}\text { Periode } \\
\text { (t) }\end{array}$} & \multicolumn{2}{|c|}{$\begin{array}{c}\text { Rencana Produksi Bulanan } \\
\text { (Unit) }\end{array}$} & \multicolumn{2}{|c|}{$\begin{array}{c}\text { Rencana Produksi Harian } \\
\text { (Unit) }\end{array}$} \\
\hline & & Kursi Parabola & Kursi Sofa & Kursi Parabola & Kursi Sofa \\
\hline Juli 2007 & 13 & 903 & 436 & 35 & 17 \\
\hline Agustus & 14 & 905 & 437 & 35 & 17 \\
\hline September & 15 & 907 & 439 & 36 & 18 \\
\hline Oktober & 16 & 909 & 440 & 35 & 17 \\
\hline November & 17 & 911 & 441 & 38 & 18 \\
\hline Desember & 18 & 913 & 443 & 35 & 17 \\
\hline Januari 2008 & 19 & 916 & 444 & 38 & 19 \\
\hline Februari & 20 & 918 & 445 & 42 & 20 \\
\hline Maret & 21 & 920 & 447 & 37 & 18 \\
\hline April & 22 & 922 & 448 & 37 & 18 \\
\hline Mei & 23 & 924 & 450 & 38 & 19 \\
\hline Juni & 24 & 926 & 451 & 36 & 17 \\
\hline
\end{tabular}

Sumber: data diolah 
pengiriman perbulan $4 \times$ pesan, dengan waktu siklus pemesanan adalah 7 hari. Hasil perhitungan rencana kebutuhan bahan baku untuk 12 periode kedepan dapat dilihat pada Tabel 4.

Biaya-biaya persediaan. Di bawah ini adalah data biaya persediaan pada periode lalu atau periode ke-12, bulan Juni 2007 antara lain:

1. Harga Bahan Dasar

2. Biaya Pemesanan $1 \times$ pesan $(\mathrm{S})$

3. Biaya penyimpanan $(\mathrm{H})$ total biaya penyimpanan periode 12 (Juni) sebesar Rp7.861.250,00

Biaya penyimpanan $/ \mathrm{kg} / \mathrm{bln}$ sebesar Rp314,45/kg/ bulan.

Pada biaya-biaya persediaan diasumsikan terjadi kenaikan setiap bulan. Asumsi kenaikan biaya-biaya persediaan tersebut berdasarkan laporan laju tingkat inflasi yang diperkirakan oleh Bank Indonesia.

Tabel 2. Hasil Perhitungan Rencana Produksi Harian dan Perhitungan Kebutuhan Bahan Baku

\begin{tabular}{|c|c|c|c|c|c|c|c|c|c|c|}
\hline \multirow{3}{*}{ Bulan } & \multicolumn{4}{|c|}{ Kursi Parabola (lonjor) } & \multicolumn{5}{|c|}{ Kursi Sofa (lonjor) } & \multirow{3}{*}{ Total (lonjor) } \\
\hline & \multirow{2}{*}{ (Unit) } & \multicolumn{3}{|c|}{$\begin{array}{c}\text { Kebutuhan Bahan Baku } \\
\text { (lonjor) }\end{array}$} & \multirow[b]{2}{*}{ (Unit) } & \multicolumn{4}{|c|}{$\begin{array}{c}\text { Kebutuhan Bahan Baku } \\
\text { (lonjor) }\end{array}$} & \\
\hline & & $\begin{array}{l}\varnothing \mathbf{3 2} \\
\mathbf{m m}\end{array}$ & $\begin{array}{c}\varnothing \mathbf{3 0} \\
\mathbf{m m}\end{array}$ & $\begin{array}{c}\varnothing 12 \\
\mathbf{m m}\end{array}$ & & $\begin{array}{c}\varnothing \mathbf{3 4} \\
\mathbf{m m}\end{array}$ & $\begin{array}{l}\varnothing \mathbf{3 2} \\
\mathbf{m m}\end{array}$ & $\begin{array}{c}\varnothing \mathbf{2 8} \\
\mathbf{m m}\end{array}$ & $\begin{array}{c}\varnothing \mathbf{1 2} \\
\mathbf{m m}\end{array}$ & \\
\hline \multicolumn{11}{|l|}{ Tahun 2007} \\
\hline Juli & 35 & 31 & 33 & 70 & 17 & 7 & 11 & 41 & 18 & 211 \\
\hline Agustus & 35 & 31 & 33 & 64 & 17 & 7 & 11 & 41 & 18 & 205 \\
\hline Sertember & 36 & 32 & 34 & 67 & 18 & 8 & 12 & 43 & 19 & 215 \\
\hline Oktober & 35 & 31 & 33 & 65 & 17 & 7 & 11 & 41 & 18 & 241 \\
\hline November & 38 & 34 & 36 & 70 & 18 & 8 & 12 & 45 & 20 & 225 \\
\hline Desember & 35 & 31 & 33 & 65 & 17 & 7 & 11 & 41 & 19 & 207 \\
\hline \multicolumn{11}{|l|}{ Tahun 2008} \\
\hline Januari & 38 & 34 & 36 & 71 & 19 & 8 & 12 & 45 & 20 & 237 \\
\hline februari & 42 & 37 & 39 & 77 & 20 & 9 & 13 & 49 & 22 & 257 \\
\hline Maret & 37 & 33 & 35 & 68 & 18 & 8 & 12 & 43 & 20 & 219 \\
\hline April & 37 & 33 & 35 & 68 & 18 & 8 & 12 & 43 & 20 & 229 \\
\hline Mei & 38 & 34 & 36 & 71 & 19 & 8 & 12 & 45 & 20 & 237 \\
\hline Juni & 36 & 32 & 33 & 66 & 17 & 8 & 11 & 42 & 19 & 220 \\
\hline
\end{tabular}

Sumber: data diolah

Tabel 3. Hasil Perhitungan Kebutuhan Bahan Baku Harian

\begin{tabular}{|c|c|c|c|c|c|c|c|c|c|c|c|c|}
\hline \multirow{3}{*}{ Bulan } & \multicolumn{5}{|c|}{ Kursi Parabola } & \multicolumn{6}{|c|}{ Kursi Sofa } & \multirow{3}{*}{$\begin{array}{c}\text { Total } \\
\text { (kg) }\end{array}$} \\
\hline & \multirow[b]{2}{*}{ (Unit) } & \multicolumn{4}{|c|}{ Kebutuhan Bahan Baku (kg) } & \multirow[b]{2}{*}{ (Unit) } & \multicolumn{5}{|c|}{ Kebutuhan Bahan Baku (kg) } & \\
\hline & & $\begin{array}{c}\varnothing 32 \\
\mathbf{m m}\end{array}$ & $\begin{array}{c}\varnothing \mathbf{3 0} \\
\mathbf{m m}\end{array}$ & $\begin{array}{c}\varnothing 12 \\
\text { mm }\end{array}$ & $\begin{array}{l}\varnothing \mathbf{3} \\
\mathbf{m m}\end{array}$ & & $\begin{array}{c}\varnothing \mathbf{3 4} \\
\mathbf{m m}\end{array}$ & $\begin{array}{c}\varnothing 32 \\
\text { mm }\end{array}$ & $\begin{array}{l}\varnothing \mathbf{2 8} \\
\mathbf{m m}\end{array}$ & $\begin{array}{l}\varnothing 12 \\
\mathbf{m m}\end{array}$ & $\begin{array}{l}\varnothing \mathbf{3} \\
\mathbf{m m}\end{array}$ & \\
\hline \multicolumn{13}{|l|}{ Tahun 2007} \\
\hline Juli & 35 & 192,44 & 199,68 & 191,74 & 10,42 & 17 & 44,76 & 66,71 & 241,40 & 53,66 & 11,74 & 990,42 \\
\hline Agustus & 35 & 192,88 & 200,01 & 192,18 & 10,44 & 17 & 44,90 & 66,92 & 242,16 & 53,83 & 11,77 & 993,03 \\
\hline September & 36 & 201,06 & 208,63 & 200,33 & 10,88 & 18 & 46,84 & 69,82 & 252,64 & 56,16 & 12,29 & 1035,48 \\
\hline Oktober & 35 & 193,77 & 201,06 & 193,06 & 10,49 & 17 & 45,18 & 67,34 & 243,68 & 54,17 & 11,85 & 998,27 \\
\hline November & 38 & 210,40 & 218,31 & 209,63 & 11,39 & 18 & 49,10 & 73,18 & 264,81 & 58,87 & 12,86 & 1084,29 \\
\hline Desember & 35 & 194,65 & 201,97 & 193,94 & 10,53 & 17 & 45,46 & 67,76 & 245,20 & 54,51 & 11,93 & 1003,50 \\
\hline \multicolumn{13}{|l|}{ Tahun 2008} \\
\hline Januari & 38 & 211,35 & 219,30 & 210,58 & 11,45 & 19 & 49,40 & 73,63 & 266,45 & 59,23 & 12,95 & 1089,96 \\
\hline Februari & 42 & 231,35 & 239,78 & 230,25 & 12,52 & 20 & 54,06 & 80,58 & 291,57 & 64,81 & 14,16 & 1192,15 \\
\hline Maret & 37 & 203,82 & 211,48 & 203,07 & 11,04 & 18 & 47,72 & 71,12 & 257,37 & 57,21 & 12,52 & 1051,81 \\
\hline April & 37 & 204,28 & 211,96 & 203,53 & 11,06 & 18 & 47,87 & 71,34 & 258,16 & 57,39 & 12,54 & 1054,53 \\
\hline Mei & 38 & 213,27 & 221,29 & 212,49 & 11,55 & 19 & 50,01 & 75,54 & 269,74 & 59,96 & 13,13 & 1101,31 \\
\hline Juni & 36 & 197,30 & 204,72 & 196,58 & 10,68 & 17 & 46,31 & 69,02 & 249,75 & 55,52 & 12,14 & 1019,21 \\
\hline
\end{tabular}

Sumber: data diolah 
Tingkat inventory rata-rata. Setelah diketahui hasil perhitungan rencana kebutuhan bahan baku maka langkah selanjutnya adalah membandingkan tingkat inventory rata-rata antara metode Just in Time (JIT) dan metode Economic Order Quantity (EOQ) ditunjukkan pada Tabel 5.

Pada Metode Just in Time (JIT) rata-rata tingkat Inventory didapat dari penjumlahan Inventory awal dan Inventory akhir yang kemudian dibagi 2 , untuk periode 13 didapat tingkat Inventory rata-rata sebesar $763,18 \mathrm{~kg}$.

Sedangkan pada Metode Economic Order Quantity (EOQ), tingkat Inventory rata-rata didapat dengan menjumlahkan safety stock dengan Kuantitas Pemesanan dibagi 2. Sehingga didapat besarnya tingkat inventory rata-rata untuk periode 13 (Juli) sebesar 3883,35. untuk tingkat inventory rata-rata 12 periode ke depan dapat dilihat pada Tabel 5.

Total Inventory Cost (TIC). Berdasarkan hasil perhitungan untuk mencari besarnya nilai Total Inventory Cost (TIC) yang di dalamnya terdapat tiga elemen biaya, yaitu biaya pembelian, biaya pemesanan, serta biaya penyimpanan didapat TIC untuk metode Just in Time (JIT) pada periode 13 sebesar Rp233.129.629,71. Sedangkan untuk metode Economic Order Quantity (EOQ) pada periode 13 adalah sebesar Rp234.171.969,21 Berdasarkan perhitungan Total Inventory Cost
Tabel 4. Rencan Kebtuhan Bahan Baku dengan Metode EOQ (Economic Order Quantity)

\begin{tabular}{|c|c|c|c|}
\hline Bulan & $\begin{array}{c}Q(\text { eoq }) \\
1 \times \text { pesan } \\
(\mathbf{k g})\end{array}$ & Fp & $\begin{array}{c}\mathbf{Q}[\mathrm{EOQ}] \\
(\mathbf{k g})\end{array}$ \\
\hline Juli 2007 & 6961,84 & 4 & 25936,11 \\
\hline Agustus & 7022,48 & 4 & 26196,59 \\
\hline September & 7089,03 & 4 & 26472,80 \\
\hline November & 7151,58 & 4 & 26734,61 \\
\hline Desember & 7210,35 & 4 & 26982,71 \\
\hline Oktober & 7265,50 & 4 & 27217,69 \\
\hline Januari 2008 & 7317,25 & 4 & 27440,34 \\
\hline Februari & 7365,79 & 4 & 27651,23 \\
\hline Maret & 7411,32 & 4 & 27851,16 \\
\hline April & 7454,03 & 4 & 28040,91 \\
\hline Mei & 7494,10 & 4 & 28220,99 \\
\hline Juni & 7531,72 & 4 & 28392,05 \\
\hline
\end{tabular}

(TIC) secara keseluruhan (periode waktu 1 tahun) dengan menerapkan metode Just In Time (JIT) didapat Total Inventory Cost (TIC) sebesar Rp5.012.483.943,59sedangkandenganmenerapkan Economic Order Quantity (EOQ) didapatkan Total Inventory Cost (TIC) sebesar Rp518.088.399,86. Jadi metode perencanaan pengendalian persediaan yang dipilih adalah metode Just in Time (JIT) dengan penghematan sebesar Rp5.604.456,27.

Penerapan metode Just in Time (JIT) untuk rencana pemesanan bahan baku. Dengan menggunakan metode Just in Time (JIT), jumlah pemesanan yang dilakukan setiap bulan sebanyak 22 kali dengan kapasitas sekali pesan yaitu

Tabel 5. Hasil Perhitungan Rata-rata Tingkat Inventory

\begin{tabular}{|c|c|c|c|c|c|c|c|}
\hline \multirow{2}{*}{ Bulan } & \multirow{2}{*}{$\begin{array}{l}\text { Periode } \\
\text { (t) }\end{array}$} & \multicolumn{3}{|c|}{$\begin{array}{l}\text { Just In Time } \\
\text { (JIT) }\end{array}$} & \multicolumn{3}{|c|}{$\begin{array}{c}\text { Economic Order Quantity } \\
\text { (EOQ) }\end{array}$} \\
\hline & & $\begin{array}{c}\text { I awal } \\
(\mathbf{t})\end{array}$ & $\begin{array}{c}\text { I akhir } \\
(\mathbf{k g})\end{array}$ & $\overline{\mathrm{I}}$ & $\begin{array}{c}\text { I awal } \\
(\mathbf{t})\end{array}$ & $\begin{array}{c}\text { I akhir } \\
(\mathbf{k g})\end{array}$ & $\overline{\mathrm{I}}$ \\
\hline \multicolumn{8}{|l|}{ Tahun 2007} \\
\hline Juli & 13 & 438,58 & 1087,78 & 763,18 & 438,58 & 623,88 & 3883,35 \\
\hline Agustus & 14 & 1087,78 & 1668,92 & 1378,35 & 623,88 & 1001,61 & 3913,68 \\
\hline September & 15 & 1668,92 & 2182,01 & 1925,46 & 1001,61 & 1587,50 & 3946,95 \\
\hline November & 16 & 2182,01 & 2627,04 & 2404,52 & 1587,50 & 2367,14 & 3978,23 \\
\hline Desember & 17 & 2627,04 & 3003,99 & 2815,52 & 2367,14 & 3326,81 & 4007,61 \\
\hline Oktober & 18 & 3003,99 & 3312,91 & 3158,45 & 3326,81 & 4453,42 & 40035,18 \\
\hline \multicolumn{8}{|l|}{ Tahun 2008} \\
\hline Januari & 19 & 3312,91 & 3553,75 & 3433,33 & 4453,42 & 5734,61 & 4061,96 \\
\hline Februari & 20 & 3553,75 & 3726,54 & 3640,14 & 5734,61 & 7158,63 & 4085,33 \\
\hline Maret & 21 & 3726,54 & 3831,28 & 3778,91 & 7158,63 & 8714,52 & 4108,09 \\
\hline April & 22 & 3831,28 & 3867,96 & 3849,62 & 8714,52 & 10392,11 & 4129,45 \\
\hline Mei & 23 & 3867,96 & 3836,56 & 3852,26 & 10392,11 & 12181,71 & 4149,49 \\
\hline Juni & 24 & 3836,56 & 3737,13 & 3786,84 & 12181,71 & 14074,33 & 4168,29 \\
\hline$\Sigma$ & & & 36435,86 & 34786,59 & & 71616,26 & 48466,70 \\
\hline
\end{tabular}

Sumber: data diolah 
$1200 \mathrm{~kg}$, untuk satu kali pemesanan adalah 1 kanban pemasok.ketepatan perhitungan waktu dan jumlah bahan baku dari supplier sangat berperan penting dalam menjalankan metode ini.

\section{SIMPULAN}

Dengan penerapan metode Just in Time (JIT) dan Economic Order Quantity (EOQ) untuk periode prencanaan selama 1 tahun ke depan dihasilkan Total Inventory Cost (TIC) untuk metode Just in Time (JIT) sebesar Rp5.012.483,59dan Total Inventory Cost (TIC) untuk metode Economic Order Quantity (EOQ) sebesar Rp5.018.088.399,86 Sehingga apabila menerapkan metode Just in Time (JIT) didapat penghematan Total Inventory Cost (TIC) sebesar Rp5.604.456,27. Penghematan terjadi pada biaya penyimpanan (holding cost) dengan kuantitas persediaan rata-rata $(\overline{\mathrm{I}})$ yang lebih rendah.

\section{DAFTAR PUSTAKA}

Ahyari, Agus. 1996. Manajemen Produksi. Yogyakarta: BPFE.

Assauri, Teguh. 1998. Manajemen Produksi dan Operasi. Jakarta: Fakultas Ekonomi UI.

Biegel, Jhon E. 1992. Pengendalian Produksi suatu Pendekatan Kuantitatif. Jakarta: Akademika Pressindo.

Gaperz, Vincent. 1998. Production Planning and Inventory Control Berdasarkan Pendekatan Sistem Terintegritas MRP III dan JIT Menuju Manufakturing 21. Jakarta: Gramedia Pustaka Tama.

Herjanto, Eddy. 1999. Manajemen Produksi dan Operasi. Jakarta: Grashindo.

Rangkuti, Freddy. 1998. Manajemen Persediaan: Aplikasi di Bidang Bisnis. Jakarta: PT Raja Grafindo Persada.

Render, Barry, dan Heizer, Joy. 2001. Prinsip-prinsip Manajemen Operasi. Jakarta: Salemba Empat. 